\title{
EL DERECHO INTERNACIONAL PRIVADO Y LOS PROCESOS GLOBALIZADORES
}

\section{Carlos Clerc*}

\author{
Fecha de recibido: 22 de agosto de 2013 \\ Fecha de aprobado: 28 de octubre de 2013 \\ Artículo de reflexión
}

Forma de citación: Clerc, C. (2013). El Derecho Internacional Privado y los procesos globalizadores. Revista Prolegómenos. Derechos y Valores, 16, 32, 15-30.

\section{Resumen}

El artículo se propone dar cuenta de las mutaciones por las que ha atravesado el Derecho Internacional Privado como consecuencia de los procesos globalizadores que tuvieron lugar hacia los inicios de la década de los 90. La emergencia de nuevos patrones de interrelación que han comenzado a darse entre las naciones, tales como la regionalidad, al supranacionalidad, la transnacionalidad, etc., han redefinido las relaciones tradicionales entre los estados generando nuevos procesos de interacción jurídico-políticos entre ellos.

La crisis del modelo de soberanía nacional estructurado en torno a una concepción territorialista de la jurisdicción, entre otras cosas, han relativizado el rol del Estado como el "sujeto-único" de las relaciones internacionales. En efecto, la aparición de nuevos actores, de nuevas prácticas, de nuevos discursos, etc., ha reconfigurado las relaciones de fuerzas y los intereses que las estructuran. La redefinición del binomio «soberanía nacional / jurisdicción internacional» a la luz de los procesos globalizadores y de la regionalidad emergente, ha creado un nuevo espacio de interacción que requiere ser formalizado y visibilizado. Para ello, el presente artículo propone, en primer lugar, delimitar la posición y naturaleza jurídica del Derecho Internacional Privado en el contexto de un Derecho global diversificado y a la luz de las nuevas prácticas emergentes y su enmarcamientos jurídicos; $y$, en segundo lugar, identificar algunos de los problemas que se plantean en este sector del ordenamiento jurídico, con relación al Derecho de la Integración, a la regionalidad y a la supranacionalidad bajo las que se inscriben las relaciones bilaterales entre las naciones por un lado $y$, por el otro, entre las naciones y el sector privado.

El presente artículo actualiza algunas cuestiones que ya fueron abordadas en una investigación más vasta emprendida durante los años 2010-2011, a propósito de las continuidades, rupturas y tensiones que se dan entre el Derecho Internacional Privado y el Derecho de base estatal.

\footnotetext{
Abogado Universidad de Buenos Aires (UBA). Especialista en Derecho de los Recursos Naturales, UBA. Doctor en Derecho, UBA. Ex Rector de la Universidad Nacional de Lomas de Zamora (UNLZ). Profesor Titular Ordinario de Derecho Civil IV, UNLZ. Profesor Titular Regular de Elementos de Derechos Reales, UBA, Profesor Titular de Derechos Reales e Intelectuales de la Facultad de Ciencias Jurídicas de la Universidad del Museo Social Argenti. Director del Instituto de Derecho Civil, UNLZ. Secretario de Postgrado y Director de la carrera de Doctorado en Derecho, UNLZ. Profesor invitado en las universidades de León (España), Deusto (España), Verona (Italia), Pavia (Italia), Ferrara (Italia), Trieste (Italia), Messina (Italia), Rijeka (Croacia), Salzburgo (Austria), Uberlandia (Brasil), Iberoamericana (Mexico), entre otras.
} 


\title{
Palabras Clave
}

Derecho Internacional Privado, Procesos globalizadores, Lex mercatoria.

\section{PRIVATE INTERNATIONAL LAW AND GLOBALIZATION PROCESSES}

\begin{abstract}
This article aims to account the mutations which private international law has gone through because of globalization processes that took place at the beginning of the decade of the " 90 s. The emergence of new patterns of interaction among nations, such as regionality, supranationality, transnationality, etc.., have redefined, based on these associative instances, traditional relations between states, generating new legal and political interaction processes between them. This article, emerged as a contemporary reflection of wider research undertaken on the topic addressed during the years 2010-2011, examines the continuities, ruptures and tensions that exist between private international law and state-based law.

Additionally, the crisis of national sovereignty structured around a territorialist conception of jurisdiction, among others, has played down the role of the State as the "only subject" of international relations. Indeed, the emergence of new actors, new practices, new discourses, etc..., has reshaped the balance of power and interests that structure it. The redefinition of the "national sovereignty / international jurisdiction" pairing in the light of globalization processes and emerging regionalism, has created a new space for interaction that needs to be formalized and made visible. To this end, this paper proposes, first, to define the position and legal nature of private international law in the context of a diversified global law and in the light of new and emerging legal practices with their respective legal frames and second, to identify some of the problems that arise in this area of law, regarding Integration Law, regionality, and supranationality under which bilateral relations between nations and between them and the private sector enroll.
\end{abstract}

\section{Keywords}

Private International Law, Globalization processes, Lex Mercatoria

\section{DIREITO INTERNACIONAL PRIVADO E PROCESSOS GLOBALIZANTES}

\begin{abstract}
Resumo
Este artigo tem como objetivo explicar as mutações que o direito internacional privado passou por causa dos processos de globalização, que teve lugar no início da década dos anos 90 . O surgimento de novos padrões de interação entre as nações, como a regionalidade, supranacionalidade, transnacionalidade, etc. Têm redefinido, com base nesses casos associativos, as relações tradicionais entre estados, gerando novos processos de interação política e jurídica entre eles. Este artigo surgiu como uma reflexão contemporânea da pesquisa mais ampla realizada sobre o tema abordado durante os anos de 2010-2011 examina as continuidades, rupturas e tensões que existem entre o direito internacional privado e direito baseado no estado.

Além disso, a crise da soberania nacional estruturado em torno de uma concepção territorialista de jurisdição, entre outros, minimizou o papel do Estado como o "único assunto" das relações
\end{abstract}


internacionais. De fato, o surgimento de novos atores, novas práticas, novo discursos, etc., remodelaram o equilibrio de poder e interesses que estrutura de TI. A redefinição do emparelhamento "soberania nacional / internacional jurisdição" à luz dos processos de globalização $e$ regionalismo emergente, riou um novo espaço de interação que precisa ser formalizada $e$ tornada visível. Para este fim, este trabalho propõe, em primeiro lugar, para definir a posição e natureza jurídica do direito internacional privado no contexto de uma lei global diversificada e à luz de práticas jurídicas novas e emergentes com seus respectivos quadros legais e, segundo, para identificar algumas dos problemas que se colocam neste domínio de direito, sobre direito da Integração, regionalidade e supranacionalidade ao abrigo do qual as relações bilaterais entre as nações e entre estes eo setor privado se inscrever.

\section{Palavras-chave}

Direito Internacional Privado, Processos de globalização, Lex Mercatoria.

\section{INTRODUCCIÓN}

Los procesos globalizadores, desencadenados durante la última década del siglo pasado, han dado lugar a la creación de una verdadera zona de interacción jurisdiccional donde lo público, lo privado, lo nacional, lo regional y lo internacional ingresan en complejas dialécticas generando tensiones tales que desbordan las previsiones normativas del Derecho Internacional Privado tradicional imponiéndole una ampliación de ellas, lo cual constituye un elemento clave para conferirle a la expansiva actividad comercial transnacional un marco legal bajo el cual regular su actuación y, asimismo, la posibilidad de construir un sistema internacional innovador $y$ fundado en complementariedades productivas antes que en exclusiones, en repartos selectivos a la riqueza, o bien, en imposiciones unilaterales por parte de los grupos económicos.

El escenario del problema, tal como nos ha sido posible identificarlo, se encuentra atravesado por dos concepciones antagónicas: (i) una concepción estatizadora que postula a un Estado como agente nivelador de las distorsiones producidas por el mercado, y (ii) una concepción privatista que postula la expansión irrestricta (no-regulada) de la actividad comercial y financiera transnacional instituyendo a la llamada nueva Lex Mercatoria como el sistema normativo por medio del cual, los intereses privados se transforman en derecho universal aplicable y pauta de valoración en la resolución de controversias.

\section{POSICIÓN Y NATURALEZA JURÍDICA DEL DERECHO INTERNACIONAL PRIVADO EN EL DERECHO INTERNACIONAL}

Tradicionalmente, el Derecho Internacional General se ha dividido en dos grandes esferas: $a$. El derecho Internacional Público y b. El Derecho Internacional Privado (en adelante DIP).

El Derecho Internacional general, observa Pizzolo (2010, pp. 4-5), conforma la matriz normativa originaria instituyente de todo el orden jurídico internacional y cuyo objeto fundamental consiste en regular las relaciones entre los estados. Sin embargo, en el orden de la notable expansión experimentada por el Derecho Internacional en materia de derechos humanos, su objeto se vio ampliado, lo mismo que el régimen de obligaciones y deberes a las que el Estado se encuentra sujeto, desplazando la inter-estatalidad con base en la cual se estructura el DIP hacia la intra-estatalidad, es decir, hacia las relaciones Estado-sujeto-conglomerado-social.

Podestá Costa (1988), agrega allí que bajo la esfera del Derecho Internacional deben incluirse no solo las relaciones jurídicas de base interestatal 
sino aquellas que se establecen entre los sujetos de derecho internacional.

En este sentido, siguiendo una doctrina autorizada (Pizzolo, 2010, p. 5 \& Sorensen, 1994, p. 95); el Derecho Internacional General puede definirse a partir de cuatro características fundamentales:

a) En tanto derecho convencional, en el sentido de que sus fuentes proceden de convenciones, tratados, acuerdos, etc. En esta sección debe incluirse al derecho internacional en materia de derechos humanos y al Derecho Internacional Humanitario.

b) En tanto derecho de cooperación, en el sentido de las solidaridades interestatales que se crean a instancias del cumplimiento de los tratados.

c) Como derecho de coordinación por cuanto el orden jurídico internacional conforma la matriz que pone en conexión las relaciones interestatales con los dispositivos, mecanismos, operadores, agentes, órganos jurisdiccionales, etc., necesarios y funcionales al cumplimiento de las obligaciones internacionales contraídas. Dichas relaciones se dan (i); entre los Estados; (ii) entre estos y las organizaciones internacionales y (iii), las que se establecen recíprocamente.

d) Como derecho de integración-asociaciónarmonización.

- Derecho de integración. Cuando el Derecho Internacional general se aplica regional o subregionalmente, como es el caso del Derecho Comunitario Europeo o el Mercosur y cuyos fines se destinan a la instauración de un derecho de carácter supranacional con miras a desencadenar un proceso de integración.

- Derecho de asociación. Será derecho de asociación, observa Moya Domínguez, por cuanto su objetivo consiste en «conformar una nueva unidad económica, producto de la suma o fusión de los distintos ámbitos espaciales económicos» (Citada por Basaldúa, 1999, p. 7).
- Derecho de armonización. Será, asimismo, un derecho de armonización por cuanto su aplicabilidad regional dependerá del grado de compatibilización alcanzado por los derechos nacionales en la reducción/minimización de las asimetrías que conspiran contra el proceso de integración.

\section{DERECHO INTERNACIONAL PRIVADO}

En el marco de las precisiones anteriores, procuraremos ahora, en primer lugar, proveer una definición del DIP; luego, su caracterización jurídica $y$, por último, sus incumbencias y la materia que regula.

Definición del DIP. Podemos definir al Derecho Internacional Privado como el conjunto o sistema normativo del que deriva la ley aplicable a las llamadas relaciones jurídicas internacionales $y$, por lo mismo, sujeta a más de una jurisdicción.

La expresión Derecho Internacional Privado fue acuñada por Joseph Story (1779-1845), Juez del Tribunal Supremo de Estados Unidos, quien la utilizara por primera vez en el año 1834 en una obra de su autoría: Comentarios sobre los Conflictos de Leyes, en la cual procuraba construir una solución armonizante entre el derecho extranjero y el derecho interno cuando ambos concurrían a instancias de un conflicto. Ya sea referido a contratos, sucesiones, matrimonios, divorcios, etc., la cuestión se centraba en determinar cuál era, como entonces, el derecho aplicable al caso (Pérez, 2002). Sin embargo, la expresión Derecho Internacional Privado es ambigua y, en opinión de Espinar (2008), también inexacta, pues el Derecho Internacional Privado es, ante todo, derecho interno, derecho estatal y, agrega el jurista «(...) El Derecho internacional privado constituye una rama de cada Sistema jurídico particular. Es Derecho interno y su calificativo de «internacional» hace exclusiva referencia a la ambientación plurilegislativa de un tipo específico de supuestos» (Espinar, 2008, p. 25). 
Y, asimismo, no es un derecho privado pues, como lo veremos seguidamente, no caen bajo su órbita tan sólo las relaciones jurídicas entre particulares sino también aquellas relaciones en las que una de sus partes es un sujeto de Derecho Internacional Público, como puede serlo, por ejemplo, un Estado).

El DIP puede ser definido como aquella disciplina que regula las relaciones de los sujetos de derecho internacional con los Estados en materia de conflictos, pretensiones o peticiones de carácter estrictamente iusprivatista.

Caen bajo la órbita de este sector del ordenamiento, todas aquellas controversias que se plantean en una relación jurídica donde uno de los sujetos/ objetos es extranjero.

\subsection{Caracterización jurídica del Derecho Internacional Privado}

En atención a la caracterización que hemos llevado a cabo con respecto al Derecho Internacional General, podríamos decir que el DIP, en el sentido descrito, es un derecho de delimitación por cuanto establece las demarcaciones jurídicas cuando convergen dos ordenamientos procedentes de diferentes legislaciones. Por lo cual, el objeto último del DIP será el determinar la ley aplicable a la controversia iusprivatista.

\section{Incumbencias del DIP}

Bajo las incumbencias caídas en la órbita del DIP, exceptuando al derecho penal, deben incluirse todas las disciplinas jurídicas y todas las controversias interpartes susceptibles de ser planteadas en sede judicial y siempre que una de ellas sea extranjera y en razón de concurrir allí ordenamientos y legislaciones diversas.

El contradictorio puede plantearse entre personas físicas o jurídicas internacionales y sobre las materias más diversas, tales como ciudadanía/ nacionalidad de los hijos nacidos en territorio extranjero; controversias sucesorias, conyugales, filiales, patentes; propiedad intelectual, usos del comercio, contratos comerciales, tecnológicos, productivos, académicos, etc.

En la presente exposición nos ocuparemos de las relaciones jurídicas internacionales privadas cuando una de las partes involucra al propio Estado.

\section{EL DERECHO INTERNACIONAL PRIVADO A LA LUZ DE LOS PROCESOS GLOBALIZADORES}

Premisa. Los cambiantes escenarios actuales, el entrecruzamiento de las diferentes lógicas bajo las que se enmarcan hoy las relaciones privadas internacionales, (algunas de ellas excluyentes, como lo veremos luego), el desigual proceso de globalización y su expansión sesgada por los actuales poderes económicos, han venido a conmover los supuestos y las regularidades del Derecho Internacional Privado, lo mismo que sus ámbitos de regulación.

El concepto geopolítico de «frontera nacional», al menos como categoría articuladora de la soberanía con eje en lo territorial, se ha visto erosionado en sus fundamentos a partir de la notable expansión experimentada por el comercio transnacional. Ello ha dado lugar a la creación de nuevas cadenas de valor global (Alemandi, 2011) con capacidad para replicarse más allá de las fronteras nacionales y de lo que se han generado espacios globales de interacción inéditos e impensables tan solo dos décadas atrás. De ahí que, el alcance jurídico y normativo del DIP tradicional, por cierto, diseñado y concebido para un sistema internacional basado en un modelo territorial, articulado en torno a la lógica «centro/periferia» y al concepto de soberanía, viera superada sus previsiones normativas.

En efecto, la brecha que se constata entre la intensidad y expansión bajo la cual se han desencadenado los procesos globalizadores, y su expresión en las normas jurídicas, sorprende a un DIP en un cierto estado de insuficiencia normativa, lo cual, forzosamente, retorna bajo 
la forma de un vacío regulatorio, propicio, por lo demás, para la reproducción de inequidades y asimetrías endémicas a nivel global y creando otras nuevas y en el que ha favorecido la instalación de la llamada nueva Lex Mercatoria.

Este vacío regulatorio ha hecho surgir relaciones comerciales y contractuales concertadas al margen o en prescindencia de los ordenamientos nacionales favoreciendo, en primer lugar, la proliferación de normas de uso, contextualmente generadas según intereses de parte, las cuales son impuestas luego por la sociedad internacional como parámetros indicativos y/o directrices objetivas desde las cuales se deben resolver las controversias inter partes que puedan suscitarse; en segundo lugar, haciendo que la actividad comercial transnacional se concentre siguiendo las líneas de fuerza trazadas por las hegemonías económicas preexistentes dejando por fuera del juego económico global a numerosos actores comerciales que no gozan de las ventajas competitivas que detentan las empresas concentradas y los grandes consorcios.

Dichas concentraciones, observa Amin Ferraz (2004), se constituyen bajo la forma de conglomerados operativos, ya sea de integración horizontal o vertical, al modo de los llamados industry complex (complejos industriales), sin «concentración jurídica»,(inconexos en el plano jurídico y societario empero, vinculados y dependientes en el plano operativo y económico, configuración esta que, en razón de su invisibilidad, escapa fácilmente al derecho aplicable) por oposición a la fusión que requiere, en este caso, la constitución de una persona jurídica. Esta modalidad, llamada «concentración económica sin concentración jurídica» (Molina, 2009) surgida en EE.UU y luego instaurada en América Latina hacia los años 90, fue ideada con el objeto de eludir los controles estatales y la ley de Defensa de la Competencia que prohibe fusiones empresarias en sectores estratégicos de la economía, tales como hidrocarburos, combustible, telecomunicaciones, electricidad, transporte público, etc., en razón de los perjuicios reales o potenciales que la fusión concentrativa pudiera ejercer sobre el sector económico de actuación respectiva y el interés económico general.

Sin embargo, todo ello no ocurre en el vacío, sino en conexión con procesos convergentes, entre ellos el abandono gradual de la función regulatoria y fiscalizadora del Estado como expresión del cambio de sus funciones, y que ha favorecido la expansión irrestricta de la llamada economía de conglomeración (holdings, trust, consorcios, grupos empresarios, fusiones corporativas, etc. Aspiazu et al., 2004) ${ }^{1}$ de actuación transnacional. Asimismo, el surgimiento de actores significativos en el espacio internacional de carácter no gubernamental, tales como la Organización para la Cooperación y el Desarrollo Económico (OCDE), el Banco Mundial (BM) y el Fondo Monetario Internacional (FMI), dotados, no obstante, de un poder decisorio y discrecional ejercido en representación de las corporaciones transnacionales que les han dado origen $y$, muchas veces, incursionando en terrenos de gestión $e$ incumbencia estatal.

Ahora bien, por entre aquellos procesos convergentes, llamamos la atención, acaso sobre el más crítico, en consonancia con lo señalado por Amin Ferraz (2004, pp. 40-41), según el cual la internacionalización del comercio y de la actividad económica no ha sido parejamente correlativa a la internacionalización de los controles sobre su actuación en los mercados.

\section{GLOBALIZACIÓN JURÍDICA}

\subsection{Mundialización y globalización}

Los términos, «mundialización»y «globalización», tanto en sede académica como periodística,

\footnotetext{
La economía de conglomeración alcanzaría su máxima expresión en la Argentina neoliberal de los años 90 bajo la administración del doctor Menem. Con respecto a esta modalidad, puede decirse que su dinamismo y complejidad vuelve muy difícil su sistematización ya que los tipos-base de organización/fusión/ integración/ concentración empresarial, exhiben una notable plasticidad y son objeto de mutaciones permanentes. (Vid. Azpiazua, D. \& Basualdo, E., 2004, pp. 7 y ss.).
} 
observa Baigún (2000, p. 6-7) son utilizados indistintamente como sinónimos.

Sin embargo, existe entre ellos una diferencia técnica que a continuación consignamos. Según Chesnais (1994, pp. 14 y ss.), la expresión «globalización» fue acuñada en las llamadas business management schools de Harvard, Columbia y Standford para designar al proceso de expansión del capital más allá de las economías centralmente localizadas. Mientras que el término «mundialización», en cambio, es de uso más frecuente en los estudios europeos, particularmente, franceses y que, a diferencia del concepto de globalización —de aplicación más restringida-, postula que la desregulación debe instrumentarse de un modo irrestricto, hasta supeditar la vida social y económica a los primados del capital y de sus racionalidades.

Para Chesnais (1994, p. 22) la mundialización, en modo alguno, puede ser considerada un sinónimo de la globalización, pues se trata de un proceso diferente al de la globalización. En efecto, mientras la globalización quedaría restringida al ámbito estrictamente económico, financiero y tecnológico, la mundialización, en cambio, expresa una fase específica del proceso de internacionalización del capital y de su emplazamiento totalizado a escala mundial que, en este caso, no solo implica la expansión del comercio mundial, sino que incluye allí a los rediseños jurídicos, institucionales, normativos, legislativos y políticos que dicha expansión requiere. La mundialización, en el sentido descrito, y según la definición de Chesnais (1994), puede muy bien ser utilizada como la clave explicativa e interpretativa del proceso de refuncionalización al que está sujeto el DIP, siendo la llamada Lex Mercatoria, la expresión más acabada de aquella mundialización. Por lo cual, en obsequio a la precisión y el rigor, convendría mucho más valerse de aquel término por cuanto, de lo que se trata en la cuestión bajo examen, es pues, el análisis de los impactos transformadores que la internacionalización del capital ha ejercido en el derecho de base estatal.
Ahora bien, el concepto «globalización jurídica», acreditado por el uso académico, también llamado «globalismo jurídico», posee, según Zolo (2002), una raíz claramente moderna y liberal. Su origen debe rastrearse en aquello que Kant llamará «derecho cosmopolita», concepto este reelaborado luego por Kelsen (1982) en su Teoría Pura del Derecho y en el que se postula, con base en la mediación kantiana, una internacionalización del derecho conformada por la unidad entre el derecho estatal y el derecho internacional y a lo que el propio Kelsen designara bajo la expresión postulado epistemológico (1982, p. 330-331) y que, por fuerza, conduciría a un único sistema jurídico borrando las fronteras entre uno y otro y haciendo del Derecho Internacional un derecho primitivo (Hart, 1970).

Los procesos globalizadores, para De Miguel Asensio (2001, pp. 37-38) y otros, han afectado al derecho bajo formas muy diversas, no solo impactando en los ordenamientos internos mediante el debilitamiento del concepto de soberanía y la redefinición del Estado-Nación al cual se articula, sino también y, particularmente, en el sistema internacional. En efecto, para Cadena Afanador (2001) y López Aillón (2001), la globalización jurídica ha comportado un drástico cambio en la estructuración del sistema de fuentes de derecho, no solo incrementándolas en cantidad y calidad (Bazán, 2007), sino desplazando los mecanismos de producción y aplicación a dispositivos transnacionales, como lo son en el ámbito del Derecho Internacional Público, los sistemas de protección (Interamericano, Europeo y Africano) y, en el Derecho Internacional Privado, el surgimiento de la llamada Nueva Lex Mercatoria.

\subsection{Derecho Internacional y Globalización}

No es objeto del presente artículo enumerar aquí los efectos que se recogen ejercido en el dominio del Derecho a partir de los procesos globalizadores. Señalaremos aquellos que son pertinentes y funcionales a los fines que nos hemos propuesto alcanzar en el presente trabajo; son estos: 
1. La globalización no es un fenómeno único sino la convergencia de un conjunto de fenómenos, paralelos y divergentes, con diferentes impactos. Por ello, la expresión "procesos globalizadores», aquí utilizada, es más exacta y abarcadora del fenómeno que el concepto genérico de "globalización».

2. El efecto más significativo ejercido sobre el Derecho ha sido, sin duda, el desbordamiento de los marcos regulatorios nacionales gracias a la llamada transnacionalización de los derechos (Cadena, 2001), lo cual obliga a una re-estructuración de las ciencias jurídicas en línea con los nuevos entornos globales y transnacionales.

3. En el ámbito del Derecho Internacional Privado, como lo veremos, ha sido la emergencia de un nuevo proceso de producción normativa, autogenerado en los márgenes de las potestades regulatorias de los Estados, conocida como la nueva Lex mercatoria, a la que nos referiremos seguidamente.

4. La redefinición de los derechos nacionales y su inserción en el marco de un Derecho Global (Cassese, 2005) ${ }^{2}$ como instancia superadora de aquellos $y$, al mismo tiempo, como espacio de articulación y coexistencia de los diferentes ordenamientos con eje en principios comunes (Rincón, 2008).

5. La exigencia de un pasaje o transformación epistémica en la construcción y fundamentación del Derecho por medio del cual se amplían el llamado margen de apreciación

2 El efecto de los procesos globalizadores en el Derecho, ha transformado las concepciones tradicionales de la soberanía, diluyendo las estrictas fronteras del Estado y convirtiéndolas en zonas de interacción e interrelación entre el orden jurídico interno y el orden jurídico internacional. Incluso, algunos autores se han referido a una nueva realidad jurídica global y expresan la necesidad, para esta nueva realidad, de un Estado de derecho global (Vid. Cassese, S., 2005).
/ valoración local en dirección a un margen de apreciación / valoración regional / continental del hecho jurídico (Delmas-Marty, 2006).

6. En el sector del ordenamiento referido al DIP, la globalización ha impuesto la exigencia de estructurar coordinadamente las reglas de actuación de las empresas, grupos, holdings, etc., en el nuevo espacio transnacional delimitado por los procesos globalizadores sin que ello configure supuestos de colisión o incompatibilidad normativa con los ordenamientos internos y los preceptos constitucionales sino, antes bien, aquello que Delmas-Marty llamara internormatividad (2006, p. 39), esto es, un espacio horizontal de entrecruzamiento normativo $y$ principio de funcionamiento del pluralismo jurídico, una nueva arquitectura donde el principio de coherencia interna y subsidiariedad prevalece por sobre el principio de jerarquía (Delperée, 2005).

Sin embargo, como muy bien lo señalara De Miguel Asensio (2001), el interés suscitado por el Derecho Internacional Privado (DIP) resulta sensiblemente menor en este dominio que en el frecuentado y asiduo Derecho Internacional Público, relegando a aquel a un lugar alternativo. Prueba de ello lo aportan los caudales bibliográficos y los repositorios documentales; profusos para este último y comparativamente exiguos para el primero.

Gracias a la globalización jurídica, asistimos a la instauración de un nuevo espacio internacional caracterizado por la creación de una zona de interacción entre la jurisdicción internacional y las soberanías internas, surgida pues, como consecuencia del fenómeno de internacionalización al que ya nos hemos referido. Esta zona de interacción (Cassese, 2005) se halla gobernada y regulada por el paradigma de derechos humanos.

Esta globalización jurídica, según lo observan Albanese (2008, pp. 13-45) y Grün (2006) es, 
ante todo, un fenómeno sistémico, entendiendo por ello, a un proceso que ejerce efectos orgánicos sobre conglomerados, mecanismos, dispositivos, instituciones, agentes, prácticas, valores, etc. y no ya sobre estructuras aisladas. De esta globalización jurídica, hemos visto expandirse la internacionalización de los derechos humanos cuya incidencia en los derechos internos ha operado gracias a un fenómeno concomitante y correlativo y que ha caracterizado como la constitucionalización del derecho internacional de los derechos humanos.

Sin duda, el fenómeno de internacionalización del derecho, correlativo al fenómeno de constitucionalización del derecho internacional en materia de derechos humanos, ha dado lugar a una serie de estándares o parámetros mínimos de garantía, respeto y ejercicio de ellos, por debajo de los cuales las normas nacionales que no las satisfagan se considerarán violatorios de aquellos principios.

De este modo, el paradigma de derechos humanos, en el ámbito del Derecho Internacional Público, se ha transformado en el criterio y en la pauta de valoración desde la que se regulan y se miden, con arreglo a ellas, los grados de cumplimiento de dichos estándares.

Recopilando lo avanzado hasta aquí, podemos decir que el nuevo espacio de interacción jurisdiccional ha creado una «zona de interacción» entre la soberanía interna y la jurisdicción internacional, gobernada por el paradigma de derechos humanos, con eje en algo más de cincuenta tratados y convenciones internacionales promulgados durante el último medio siglo.

Como lo veremos seguidamente, en el desarrollo de nuestro problema el ámbito del Derecho Internacional Privado presenta, con respecto al fenómeno de internacionalización descrito, algunas continuidades y rupturas, las cuales analizaremos seguidamente.

\section{CONTINUIDADES Y RUPTURAS ENTRE EL DERECHO INTERNACIONAL PÚBLICO Y EL DERECHO INTERNACIONAL PRIVADO}

El notable expansionismo que presenta el comercio internacional, básicamente de naturaleza inter-empresarial, ha dado lugar, en el ámbito del Derecho Internacional Privado, a un fenómeno concomitante y correlativo al generado en el Derecho Internacional Público y al que hemos llamado: «zona de interacción privada internacional». He aquí pues, la continuidad que es posible destacar entre ambos ordenamientos.

Sin embargo, a diferencia de lo que ocurre en el ámbito del Derecho Internacional Público, la zona de interacción se encuentra gobernada por dos paradigmas excluyentes o que, al menos, requieren una armonización concertada: (i) el paradigma de la nueva Lex mercatoria, con eje en racionalidades rentistas y (ii) el paradigma del desarrollo/crecimiento económico con proyección estatal /interestatal/ regional/inter-regional.

En esta zona de interacción privada internacional, a diferencia de la zona de interacción jurisdiccional en la que se instaurara el paradigma de derechos humanos, se verá gobernada, en cambio, por lo que hemos llamado aquí, en consonancia con cierta doctrina sociológica acreditada (Azpiazu, 2004, Sandoval/Rose-Ackerman, 2009, et. al.) ), «racionalidades rentistas».

Estas racionalidades rentistas, en tanto se oponen a las racionalidades del Estado centradas a la preservación de los intereses del conjunto marcan, pues, el punto de ruptura respecto de la zona de interacción jurisidiccional como fenómeno común y recurrente de la internacionalización del derecho al que nos hemos referido y que, en el orden mismo de esta colisión entre principios y racionalidades, puede afectar la seguridad jurídica. En este punto se produce la mayor ruptura, la mayor divergencia entre el DIP y el DI Público. 
Tal ha sido una de las conclusiones de la VII Cumbre Iberoamericana de Presidentes de Cortes Supremas y Tribunales Supremos de Justicia:

Estudiar y examinar, por expertos y juristas especializados, las implicaciones que los fenómenos globalizadores en curso comportan en relación con los rasgos definidores del Estado de Derecho y, en particular, con el principio de seguridad jurídica como postulado esencial del mismo, así como los principios de equidad y reciprocidad que deben regir a las inversiones (2002).

Por cierto, en esta zona de interacción, los Estados y sus mecanismos regulatorios y fiscalizadores se desdibujan en un escenario dominado por el primado de relaciones comerciales transnacionales $y$ en beneficio de estas últimas, y haciendo que el Derecho Internacional Privado se vuelva, por fuerza, funcional a ellas.

Esto plantea una serie de problemas, podríamos decir «sistémicos», por cuanto en aquella zona convergen racionalidades divergentes, como lo son la seguridad jurídica, las regulaciones estatales, y las exigencias de rentabilidad empresarial, haciendo que los intereses del conjunto, tal como son promovidos por la racionalidad de lo público, colisionen con los intereses corporativos en un punto de intersección crítica y excluyente.

\section{SEGURIDAD JURÍDICA EN EL DERECHO INTERNO Y EN EL DERECHO INTERNACIONAL}

El concepto de seguridad jurídica puede ser considerado como uno de los conceptos axiales del Derecho, tanto en el ámbito interno como internacional, puesto que lo atraviesa todo a lo largo de sus disciplinas y constituye, asimismo, uno de los pilares sobre el que descansa el ordenamiento interno y del que depende, inter alia, la gobernabilidad del sistema democrático.

Sobre los supuestos de la seguridad jurídica en el derecho interno, Alterini (1993, pp. 28-29), citado por Moya Domínguez (2006, pp. 28-29), identificó tres supuestos de seguridad jurídica para el derecho interno

(i) Por medio del Derecho

(ii) Como certidumbre del Derecho

(iii) Como estabilidad del Derecho

(i) por medio del derecho: cuando el ordenamiento jurídico garantiza, a través del Estado y sus instituciones políticas, la vigencia de la justicia social.

(También justicia redistributiva) y el respeto incondicional de los derechos fundamentales derivados de la ciudanía (Campillo, 2005 \& Marshall, 1998), declarando antijurídica toda acción u omisión que impida o lesione el goce de tales derechos.

(ii) como certidumbre del derecho: se refiere aquí al conjunto de certezas, regularidades, viabilidades, garantías, etc., de las que deben gozar inequívocamente los titulares de los derechos protegidos, tanto por la Constitución en el ordenamiento interno como por las convenciones y tratados en la jurisdicción internacional.

(iii) como estabilidad del derecho: entendiendo por ello a la previsibilidad del sistema judicial, su permanencia, regularidad temporal de las normas y códigos que garantizan el ejercicio de los derechos en ellos consagrados, impidiendo que los fenómenos de inflación legislativa o que ciertos componentes erráticos-política o situacionalmente configurados-, vengan a afectar o trasponer las regularidades normativas en las que se sustentan y legitiman el ejercicio de derechos.

Desafortunadamente, nuestro país, durante los últimos años, se ha transformado en un prolífico generador de ejemplos in contrario sensu de lo que debe ser la seguridad jurídica, donde la certidumbre del derecho y la previsibilidad de la que debe gozar el sistema judicial en su conjunto, ha sido sustituido, en cambio, por un sistema de intereses y beneficios que responde a las necesidades de la clase política y no del conjunto social. 


\subsection{Supuestos fundamentales de la seguridad jurídica en el Derecho Internacional}

La seguridad jurídica, ya en el dominio del Derecho Internacional, puede ser definida, con base en las consideraciones anteriores, como aquel conjunto de certezas relativas a la permanencia de las normas y principios consagrados en los convenios y tratados internacionales.

Este conjunto de certezas, equiparables a las del derecho interno, encuentran su materialización en dos principios convergentes fundamentales y bajo los que se estructura el Derecho Internacional en tanto construcción jurídica, sea público o privado, son estos pacta sunt servanda, y el carácter ius cogens de las normas consagradas en ellos.

Ambos han sido recogidos por la Convención de Viena sobre el derecho de los tratados del año 1969. El primero, en su artículo 26 establece que: «todo tratado en vigor obliga a las partes y debe ser cumplido de buena fe». El segundo, en el artículo 53:

Tratados que están en oposición con una norma imperativa de derecho internacional general (ius cogens) Es nulo todo tratado que, en el momento de su celebración esté en oposición con una norma imperativa de derecho internacional general. Para los efectos de la presente Convención, una norma imperativa de derecho internacional general es una norma aceptada y reconocida por la comunidad internacional de Estados en su conjunto como norma que no admite acuerdo en contrario y que sólo puede ser modificada por una norma ulterior de derecho internacional general que tenga el mismo carácter.

Sin duda, este principio axial, observa Hurrel (1992),es acatado por los países-parte en beneficio recíproco, si acaso consideramos que un tratado es, ante todo, un acuerdo de voluntades, siendo que su cumplimiento, agrega Moya Domínguez (2006, p. 32), es condición exigida para pertenecer a la sociedad internacional. Por ello, la falta de cumplimiento por parte de un Estado-miembro de un tratado o convención al que le hubiera soberanamente prestado su acuerdo, acarrea para este una «responsabilidad internacional $»^{3} \mathrm{y}$, en consecuencia, una grave lesión a la seguridad jurídica internacional.

Como hemos visto, los supuestos sobre los que asienta la seguridad jurídica tanto en el derecho interno como en el Derecho Internacional Público son coincidentes y se estructuran ambas, en torno a racionalidades fundadas en valores. Sin embargo, los supuestos con arreglo a los cuales se estructura la seguridad jurídica en el Derecho Internacional Privado, difieren en la racionalidad y objetivos. Así, mientras en el primer caso la seguridad jurídica conforma la base del sistema judicial y se orienta a preservar la cohesión del conjunto social, la seguridad jurídica en el DIP concerniente al comercio internacional, acuerdos, tratados, etc., y las relaciones con el Estado; parece estructurarse mucho más en torno a una racionalidad mercatoria, no-distributiva, antes que a una racionalidad basada en valores.

Ello es así, debido a que la naturaleza y objeto de la tutela, en este caso, es estrictamente iusprivatista.

En efecto, el CIADI (Centro Internacional de Arreglo de Diferencias Relativas a las Inversiones), creado por el Convenio de Washington en 1965, es un organismo arbitral cuyo objeto se dirige a poner a disposición de las partes diferentes instrumentos de conciliación y arbitraje para la solución de las controversias que pudieran surgir en materia de inversiones, ya sea entre Estados partes, o bien, entre nacionales de otros Estados partes que hayan aceptado su jurisdicción. Asimismo, el Tratado de Protección de Inversiones. Se trata pues, de acuerdos bilaterales y genéricamente se los identifica bajo la expresión

El tribunal de La Haya, con respecto a este principio, sostuvo que « (...) un Estado que ha contraído válidamente obligaciones internacionales está obligado a introducir en su legislación las modificaciones necesarias para asegurar la ejecución de los compromisos asumidos». 
genérica de Acuerdos bilaterales de promoción y protección recíproca de inversiones.

Por entre los acuerdos bilaterales de inversiones caídos bajo la jurisdicción del CIADI, señalamos: TPI (Tratados de Protección de Inversiones; TBI (Tratados bilaterales de Inversión y los llamados APPRI (Acuerdos bilaterales de promoción y protección recíproca de inversiones).

Materias tuteladas por los TPI (Tratados de Protección de Inversiones y TBI (Tratados Bilaterales de Inversión).

La protección que se le brinda a los tratados comerciales o inversiones entre Estados-parte o entre nacionales de un Estado y otro Estado-parte giran en torno a los siguientes puntos: (1) derecho a un tratamiento justo y equitativo; (2) derecho a recibir idéntico tratamiento que los inversores nacionales; (3) derecho a recibir una indemnización en caso de medidas de expropiación, directa o indirecta; derecho a libre transferencia de rentas, ganancias, beneficios económicos, etc. $y,(5)$ derecho a recibir idéntico tratamiento que el otorgado a las inversiones procedentes del país que goce de un tratamiento más favorable (cláusula de la nación más favorecida).

Por lo cual, en atención a lo expuesto, la configuración de supuestos violatorios de la seguridad jurídica en el ámbito del derecho interno y del Derecho Internacional, por fuerza, difieren de los supuestos violatorios aplicables al Derecho Internacional Privado, no solo en razón de los sujetos y objetos tutelados, sino en el orden de las racionalidades en juego. Así, mientras en los primeros asistimos a una ratio fundada en la preservación del conjunto social, en el segundo caso, asistimos a una ratio fundada en intereses privatistas y de parte.

\section{LEX MERCATORIA Y DERECHO INTERNACIONAL PRIVADO}

Lex Mercatoria, también, ius mercatorium, originariamente designaba a un conglomerado de normas jurídicas que regulaba la actividad comercial durante la primera Edad Media. Estas normas, usualmente, eran fijadas por los mismos comerciantes y artesanos y sin que interviniera allí alguna autoridad, edicto o apelación a norma superior, lo cual, transformaba a esta Lex mercatoria, en un derecho claramente consuetudinario. Debe destacarse que este ius mercatorium, surge en clara oposición al derecho de los señores feudales y a sus privilegios, y ante la insuficiencia normativa del derecho civil para proveer una respuesta adecuada al notable crecimiento de la actividad comercial. Su aplicación cayó en desuso, claro está, hacia los inicios de las grandes codificaciones jurídicas que tuvieron lugar, la primera de ellas, durante la llamada Alta Edad Media (Alfonso X el Sabio), y luego, la segunda, hacia el final del siglo XVIII. En la actualidad, se asiste a una suerte de recuperación, en el seno del DIP, de la llamada Lex mercatoria. (Tovar, 2007 \& Beguin, 1985)

¿Por qué se vincula la Lex mercatoria con el DIP?

Según un consenso muy extendido entre los juristas especializados en esta disciplina, el DIP, muy bien puede ser considerado una suerte de recuperación de la Lex mercatoria, en el sentido de configurarse en primer lugar, como una respuesta a la expansión de un comercio transnacional en el que rigen no pocas lagunas normativas $y$, en segundo lugar, como un conjunto de normas autogeneradas en un espacio sustraído a los procedimientos de generación normativa con base estatal.

La notable expansión que han experimentado las transacciones privadas en el ámbito internacional, observa Tovar Gil (2007), ha dado origen a una normativa paralela confeccionada y producida con base en criterios de uso que presenta, en este aspecto, una cierta semejanza con el ius mercatorium de la Edad Media, en el orden de lo cual, se ha convenido en llamar al DIP la Nueva Lex Mercatoria Internacional.

Ahora bien, esta homologación entre la Lex mercatoria y el Derecho Internacional Privado no es 
tan solo académica sino, antes bien, un proceso de construcción jurídico-político en el sentido de una armonización de usos y normas desde la cual se procura obtener un derecho mercantil homogéneo y legitimar en el plano normativo lo que se ha configurado en el plano de las prácticas comerciales a escala planetaria. Esto es la reproducción concomitante y contradictoria, (i) de mercados transnacionales, anónimos, ubicuos, sin base geográfica, estructurados con arreglo a racionalidades rentistas, donde la vinculación normativa entre la empresa y el Estado de origen se diluye para supeditarse bajo los principios de una Lex mercatoria supranacional, fáctica y autorregulada por sobre las soberanías e instituciones, de base típicamente estatal (Mercado, 1999). Y, (ii), el incremento de transacciones comerciales que se dan a nivel regional y subregional, como por ejemplo, el Mercosur, estructuradas, a diferencia de las primeras, con arreglo a racionalidades de desarrollo, entre ellas, la transferencia de tecnologías, circulación preferencial de bienes y servicios, flujos exportadores / importadores, etc.

Es importante señalar que dichos mercados autorregulados terminan instaurando una suerte de constitucionalismo mercantil global desde el cual los intereses corporativos se promueven al rango de una grundnorm (norma fundamental) del ordenamiento nacional e internacional (abundan ejemplos de ello en el plano internacional). En nuestro país, pueden citarse la implementación, durante los años 90, de mecanismos administrativos y legales que garantizaban a los consorcios privatizadores altas las tasas de retorno sobre las inversiones efectuadas, no sujetas al riesgo empresarial o financiero, y distorsionadas con respecto a las rentabilidades relativas de la economía (Aspiazu, 2004).

Este fenómeno, por cierto, comporta una degradación normativa del derecho como sistema comportando, por lo mismo, una lesión a los principios nacionales e internacionales sobre los que se estructura la seguridad jurídica. Asimismo, esta autorregulación de los mercados parecería disputarle al Estado el monopolio de la violencia y el de la producción legislativa, transformando lo fáctico en norma, y la norma en una mera formalidad de aplicación selectiva, prescindible o negociada.

Así, por este conducto, se da un proceso en paralelo según el cual el fortalecimiento de las normas fácticas corre parejamente al debilitamiento normativo que estas ocasionan sobre el ordenamiento legal, y donde la concentración de los poderes económicos se expande a costa de la dispersión y debilitamiento de los poderes fiscalizadores y reguladores del Estado que dicha concentración, por lo demás, forzosamente provoca.

De ello, por fuerza, resulta una degradación normativa y una lesión a la seguridad jurídica.

La globalización, observa De Miguel Asensio (2001), lejos de ser eficaz en el control o en la equiparación de estas inequidades, antes bien, las ha reproducido con mayor intensidad. Debe decirse que estas no inciden sólo en determinados sectores sociales sino que ejercen un efecto sistémico sobre el conjunto de lo social y sobre las variables macroeconómicas afectando los niveles de distribución de la riqueza, el empleo, el acceso igualitario a bienes y servicios, etc.

\section{A MODO DE CONCLUSIÓN}

La Argentina de los años 90, al igual que la mayor parte de los países latinoamericanos durante aquel período, sufrieron un proceso privatizador de instauración regional que consistió, inter alia, en la transferencia de los activos públicos del Estado hacia el sector privado. Este proceso, aún en curso, se manifestó mediante la articulación de dos fases: (i) privatización de las empresas públicas (1990-2000) y (ii) re-funcionalización del Estado como garante y replicador del rentismo corporativo.

Cabe señalar que el proceso privatizador y las prácticas económicas asociadas a este eran claramente violatorias de principios constitucionales $y$ de derechos sociales adquiridos, lo cual pudo 
«resolverse» mediante la promulgación de leyes, decretos y disposiciones legislativas de flagrante inconstitucionalidad, ( la mayoría de ellas, aún vigentes) funcionales al «nuevo modelo económico» y a la globalización hegemónica.

El DIP, concebido en el interior de la matriz liberal y destinado a tutelar la persona y sus bienes con base en los dos pilares o columnas en las que reposa el derecho civil-libertad y propiedad-, surgidas estas en el interior de una demarcación neta entre las esferas de lo privado y lo público, es hoy insuficiente. En efecto, no existe en la actualidad ámbito de actividad, discurso o práctica sustraída al efecto modelador de los procesos globalizadores.

La emergencia de nuevos contextos y escenarios, lo mismo que la configuración de nuevas tensiones y la aparición de nuevos actores, han redefinido, o mejor, conmovido los supuestos liberales en los que descansa la matriz jurídica occidental que, según creemos, comienza hoy a volverse abstracta y difusa. Así, el concepto de "persona jurídica»; "propiedad»; "sujeto», «daño individual», etc., y las dimensiones de lo público y lo privado que las articulan, deben ser revisadas a la luz del actual escenario. Hemos visto que la demora en la necesaria y perentoria revisión de nuestros ordenamientos jurídicos, particularmente en el ámbito del derecho societario y comercial (también incumbencia del DIP), genera vacíos regulatorios propicios para una expansión irrestricta y no regulada de intereses privados que prevalecen por sobre los intereses del conjunto social.

Ello genera un daño «macrosocial» (Baigún, 2000, p. 2), perpetrado por agentes trans-individuales, es decir, agentes corporativos, cuya nacionalidad, persona jurídica y elementos de conexión con el derecho aplicable, como hemos visto, es difusa, o bien, de muy difícil identificación y, a lo que debe sumarse la asombrosa capacidad mutativa de la que gozan aquellos agentes a la hora de imputárseles responsabilidades civiles o penales. Nuestros países son pródigos en ejemplos de ello. Bastaría citar los recientes acontecimientos acae- cidos en la Argentina durante el último semestre para apoyar nuestras afirmaciones.

Para concluir, diremos que a nosotros, los juristas, abogados, jueces, y todos los operadores jurídicos, nos cabe una responsabilidad y es, antes de crear derecho, la de crear consciencia sobre la cual deberá asentarse, ahora sí, el nuevo derecho. No el «terrible derecho» del que hablaba Beccaria refiriéndose al derecho penal o al que se refería Rodotà a instancias de su maravillosa obra sobre la propiedad privada y su ambigua tutela, sino un derecho centrado en la tutela de los bienes colectivos frente a las prácticas predatorias a manos de los grandes consorcios concentrados y que el Estado, en coordinación con estos, les confiere el sustento legal necesario.

Un derecho que ponga el foco de la criminalización, no ya sobre la llamada delincuencia de subsistencia, desestructurada, oportunista y violenta, sino sobre la delincuencia de acumulación, estructurada, racional, calculada y cuya violencia no se ejerce ya al modo de la delincuencia callejera y urbana, sino afectando y sesgando las leyes del país en el que opera, su Constitución, sus variables macrosociales, sus activos públicos, sus recursos. Un derecho en donde el Estado no sea ya el socio de estos grupos sino quien enmarque la actividad de ellos en la suprema ley de la que es su garante, la Constitución, siendo su primacía, la única seguridad jurídica a la cual se debe aspirar.

\section{REFERENCIAS}

AA.VV. (2002). Globalización y seguridad jurídica. Documento de Fundamentación. VII Cumbre Iberoamericana de Presidentes de Cortes Supremas y Tribunales Supremos de Justicia. México.

Albanese, S. (2008). La internacionalización del derecho constitucional y la constitucionalización del derecho internacional. En Albanese, S. El control de convencionalidad. (pp. 13-45). Buenos Aires: Ediar. 
Alemandi, M. (2011). Internacionalización empresarial, cadenas de valor globales y Mercosur. El joint venture como instrumento para la integración productiva. Ponencia presentada en el I Congreso Internacional de la Red de Integración Latinoamericana 2011. Santa Fe, Argentina: Universidad Nacional del Litoral.

Alterini, A. (1993). La inseguridad jurídica. Buenos Aires: Abeledo Perrot.

Amin, D. (2004). La concentración empresarial en el comercio internacional. El control de los grupos de sociedades en los EE.UU, la UE y el Mercosur. Tesis Doctoral. Universitat de Valenciau. Valencia: Servei de Publicacions.

Azpiazu, D. \& Basualdo, E. (2004). Las privatizaciones en la Argentina. Génesis, desarrollo $y$ principales impactos estructurales. Buenos Aires: FLACSO.

Baigún, D. (2000). La responsabilidad penal de las personas jurídicas. Ensayo de un nuevo modelo teórico. Buenos Aires: DePalma.

Bazán, V. (2007) La interacción del derecho internacional de los derechos humanos y el derecho interno en Argentina. En: Estudios Constitucionales, 5, 2, 137-183.

Beguin, J. (1985). Le Developement de la Lex Mercatoria Menace-t-il ordre juridique international ? En Mc Gill Law Journal p. 14).

Cadena, W. R. (2001). La Nueva Lex Mercatoria: Un caso pionero en la Globalización del Derecho. Papel Político, 13, 101-114.

Campillo, I. (2005). La ciudadanía social. Perspectivas y propuestas feministas. (UCM). Ponencia presentada en: VII Congreso Español de Ciencia Política y de la Administración: Democracia y Buen Gobierno. Madrid.

Capella, J. R. (coor.) Transformaciones del Derecho en la mundialización. Madrid: CGPJ
Cassese, S. (2005). Administrative Law without the State? The Challenge of Global Regulation. N.Y.U. Journal of International Law and Politics. (37): 663-694. En: Palombella, G. The Rule of Law beyond the State: Failures, Promises, and theory, International Journal of Constitutional Law, 7, 3, 2009, pp. 442-467.

Chesnais, F. (1994). La mondialisation du capital. París: Syros.

De Miguel, P. A. (2001). El Derecho Internacional Privado ante la Globalización. En AA.WV Anuario de Derecho Internacional Privado.

Delmas-Marty, M. (2006). Les forces imaginantes du droit (II): Le pluralisme ordonné. Paris: Seuil.

Delpérée, F. (2005). La communicabilité entre le droit international, le droit européen, le droit constitutionnel et le droit régional. En: Beaudrez, M., \& Di Manno, T. : Escarras, J.-C. (dir.) Liber amoricum: la communicabilité entre les systèmes juridiques. Bruxelles: Editions Juridiques Bruylant.

Espinar, J. M. (2008). Tratado Elemental de Derecho Internacional Privado. Universidad de Alcalá de Henares.

Grün, E. (2006). Las globalizaciones jurídicas. Revista Facultad de Derecho y Ciencias Políticas, 36, 105, 323-339.

Hart, H. L. A. (1970). Kelsen's Doctrine of the Unit of Law. En: Ethics and Social Justice, 4. State University of New York Press.

Hurrel, A. (1992). Teoría de los regímenes internacionales: Una perspectiva europea. Foro Internacional. El Colegio de México, 32.

Kelsen, H. (1982). Teoría Pura del Derecho. México: UNAM.

López, S. (2001). Globalización, Estado de Derecho y Seguridad Jurídica. Una Exploración sobre los efectos de la Globalización en los Poderes 
Judiciales de Iberoamérica. Ponencia presentada en la VIII Cumbre Iberoamericana de Presidentes de Cortes Supremas y Tribunales Supremos de Justicia. México.

Marshall, T. H. (1998): Ciudadanía y clase social. Madrid: Alianza Editorial.

Mercado, P. (1999). El Estado comercial abierto. La forma de gobierno de una economía desterritorializada. En: Capella, J. R. (coor.). Transformaciones del Derecho en la mundialización. Madrid: CGPJ.

Molina, C. (2009). El control de concentraciones económicas y fusiones en el régimen competitivo argentino. Cuadernos de la Maestría en Derecho, 2, 327-377.

Moya, M. T. (2006). Derecho de la Integración. Mercosur: Instituciones y Fuentes. Unión Europea y Comunidad Andina: Estudio comparado. Buenos Aires: Ediar.

Pérez, E. (2002). Derecho Internacional Privado. Vol. I y II. Madrid: UNED
Pizzolo, C. (2010). Derecho e integración regional. Comunidad andina. Mercosur. Cica. Unión Europea. Buenos Aires: Ediar.

Podestá, L. A. \& Ruda, J. M. (1988). Derecho Internacional Público. Buenos Aires: TEA

Rincón, J. G. (2008). La globalización y el derecho: la necesaria aplicación de un pluralismo jurídico real. Prolegómenos : Derechos y Valores, 11, 22: 45-55.

Sandoval, I. \& Rose-Ackerman, S. (coord.) (2009) Corrupción y transparencia: debatiendo las fronteras entre Estado, mercado y sociedad. México: Siglo XXI y UNAM.

Sorensen, M. (1994). Manual de Derecho Internacional Público. México: FCE.

Tovar, M. C. (2007) Aplicación de la lex mercatoria internacional por los árbitros. Lima Arbitration, 2, 106-125.

Zolo, D. (2002). Una crítica realista del globalismo jurídico desde Kant a Kelsen y Habermas. Revista Anales de la Cátedra Francisco Suárez, 36, 197-218. 